\title{
An inclusive city water account by integrating multiple data sources for South-East Queensland (SEQ), Australia
}

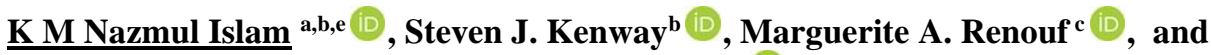 \\ Thomas Wiedmann $d$ (D) \\ ${ }^{a}$ School of Chemical Engineering, University of Queensland, QLD, 4072, Australia, ${ }^{b}$ Australian Centre for \\ Water and Environmental Biotechnology (formerly AWMC), University of Queensland, QLD, 4072, \\ Australia, ${ }^{c}$ QUT Centre for Agriculture and the Bioeconomy (CAB), Queensland University of Technology, \\ QLD, 4000, Australia, ' Sustainability Assessment Program (SAP), School of Civil and Environmental \\ Engineering, UNSW, Sydney NSW 2052, Australia, ${ }^{e}$ Institute of Forestry and Environmental Sciences, \\ University of Chittagong, Chittagong 4331, Bangladesh \\ Email: kmnazmul.islam@uq.net.au
}

\begin{abstract}
Cities are the hotspots of impacts on local and distant water resources through economic activity and consumption. More than half of the world's population lives in cities, which is expected to reach around two-thirds by 2050. Such a high level of increased urbanization calls for higher attention towards inclusive, safe, resilient, and sustainable cities (Sustainable Development Goals 11). To evaluate sustainability, inclusiveness, and resiliency pathways, a variety of sustainability indicators have been proposed, including the water footprint. The water footprint is defined as the total volume of freshwater used for the goods and services consumed. It covers both direct (e.g. drinking and cleaning) and virtual water flows (water used in the goods and services supply chain, hence also known as embedded water).

Virtual water flows through products and services produced in other locations using their water resources influence the function, prosperity, and growth of the cities. Yet, this aspect is absent in the sustainability and strategic city water footprint reduction goals of Australian cities. To fully account for the water dependencies of Australian cities, direct and virtual water flows need to be known. To this purpose, we build inclusive city water of South-East Queensland (SEQ) by combining material flow analysis (MFA) and the multiregional input-output (MRIO) model. Water consumption in SEQ is used to quantify the water footprint on local water resources and net blue virtual water import. Together, this constitutes the water footprint on national water resources. Our results show that the water footprint of SEQ on local water resources is $620 \mathrm{GL}$ with a net virtual water import of 1382 GL. Therefore, the water

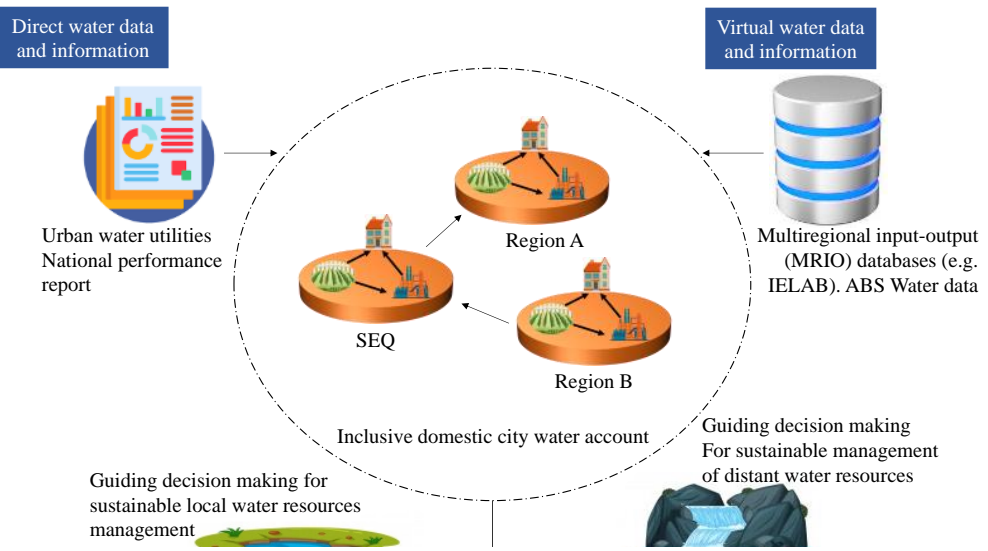
footprint of SEQ on national water resources is 2002 GL. The water

Figure 1. Conceptual figure of an inclusive city account for driving strong sustainability action in Australia cities. footprint of SEQ on local water resources consists of direct water consumption by households (192 GL) and the industrial sector (428 GL). The consumed direct water of the SEQ industrial sector flows as virtual water to SEQ (149 GL), the rest of Australia (RoAUS) (all other regions except SEQ) (211 GL), and the rest of the world (68 GL). The virtual water inflows breakdown by source regions showed that $386 \mathrm{GL}, 1019 \mathrm{GL}$, and $256 \mathrm{GL}$ of virtual water imported from the major cities (Sydney, Melbourne, Adelaide, and Perth); regional areas of NSW, Victoria, and QLD; and RoAUS, respectively. Overall, the proposed inclusive city water account can enhance subnational estimates of city water footprint for benchmarking, as well as inclusive and resilient city water planning.

Keywords: Water footprint, urban metabolism, integrated city water account 
Islam et al., An inclusive city water account by integrating multiple data sources for South-East Queensland (SEQ), Australia

\section{INTRODUCTION}

Water represents $90 \%$ of total material flows in a city, and every day around 504 GL of water is moved around the world (McDonald et al. 2014, Wolman 1965). Water can inflow and outflow from a city as direct (e.g. drinking and washing) and virtual water flows. Virtual water is the water consumed in the product supply chain and is hence also often termed embodied water. Therefore cities sustain themselves by taking water from adjacent water sources, and also consuming virtual water from the hinterlands (Athanassiadis et al. 2018). Virtual water may originate within the city boundary or outside the city boundary (Renouf and Kenway 2017). Hence, the total water footprint of a city is the summation of direct and virtual water (Chini et al. 2017). Despite this fact, urban water management benchmark programs (e.g. Water Sensitive Cities Index) focused only on direct water flows (Renouf et al. 2017). While, the Sustainable Development Goals (SDG) call for making the cities inclusive, safe, resilient, and sustainable (SDG 11). If we look at the water sustainability targets of the cities, we will observe that the importance of virtual water flows to sustain the cities is ignored, and hence in their planning. For example, Table 1 presents the water sustainability goals and targets of the cities (Brisbane, Goal Coast, and Sunshine Coast) of South East Queensland (SEQ). Water sustainability goals of these three cities are mostly focused on direct water consumption, water quality and health of the nearby water bodies, and water smart designs. This is an example of weak sustainability, non-inclusiveness regarding the importance of hinterlands, and making the cities not resilient for a future sock of water shortage in the hinterland by ignoring the magnitude (8-10 times higher than direct water) of virtual water flows.

Table 1. Water sustainability goals and targets of the cities in South East Queensland.

\begin{tabular}{|c|c|c|c|c|}
\hline City & Sustainability Goals and targets & $\begin{array}{l}\text { Water } \\
\text { consumption } \\
\text { per capita }\end{array}$ & $\begin{array}{l}\text { Year of } \\
\text { data }\end{array}$ & Reference \\
\hline Brisbane & $\begin{array}{l}\text { The city has four goals focusing on (i) a water-smart community, } \\
\text { (ii) a well-designed subtropical city, (iii) a healthy river and bay, } \\
\text { and (iv) sustainable water use. Under the goal-(i), it is mentioned } \\
\text { by } 2012 \text {, the community of the city has a high to a very high } \\
\text { level of awareness on water-smart designs and their } \\
\text { implementation. } \\
\text { Under goal-(iv), it is mentioned by } 2012 \text {, the average annual use } \\
\text { of the reticulated water supply by the city community will be } 10 \% \\
\text { of } 200 \text { liters per person per day. }\end{array}$ & $\begin{array}{l}143.8 \text { liters } \\
\text { per } \\
\text { person per day }\end{array}$ & 2010 & $\begin{array}{l}\text { (BCC 2010, Beal } \\
\text { et al. 2011) }\end{array}$ \\
\hline Gold Coast & $\begin{array}{l}\text { The Gold Coast Water Strategy 2019-2024 is based on four } \\
\text { strategic outcomes focusing on (i) healthy waters, (ii) innovative } \\
\text { water solutions, (iii) water-inspired designs, and (iv) partnerships } \\
\text { for water. In the outcome (ii), it mentioned the short-term goal of } \\
\text { increasing the use of recycled water of at least } 12,000 \text { ML per } \\
\text { year, and in the long term, it will be } 30,000 \mathrm{ML} \text {. Under the } \\
\text { outcome (iv), the short-term goal is to increase community water } \\
\text { literacy by } 10 \% \text {, and it will be } 50 \% \text { in the long run compared to } \\
\text { the } 2020 \text { baseline. }\end{array}$ & $\begin{array}{l}140.8 \text { liters } \\
\text { per } \\
\text { person per day }\end{array}$ & 2010 & $\begin{array}{l}\text { (Beal et al. 2011, } \\
\text { GCCC 2019) }\end{array}$ \\
\hline $\begin{array}{l}\text { Sunshine } \\
\text { Coast }\end{array}$ & $\begin{array}{l}\text { Under the Environment and Liveability Strategy, it has mandates } \\
\text { on waterways, wetlands, stormwater management, and } \\
\text { sustainable design. For example, under the waterways theme, it } \\
\text { mentioned by 2041, maintain and improve the ecological health } \\
\text { condition of waterways. }\end{array}$ & $\begin{array}{l}170.8 \text { liters } \\
\text { per } \\
\text { person per day }\end{array}$ & 2010 & $\begin{array}{l}\text { (Beal et al. 2011, } \\
\text { SCCC 2017) }\end{array}$ \\
\hline
\end{tabular}

Virtual water flows at the national level explored by Lenzen and Foran (2001) and (Ridoutt et al. 2018), and also at the state-level by some scholars in Australia (Lenzen 2009, Reutter et al. 2018). Direct water consumption was studied in Sydney (Randolph and Troy 2007, Troy et al. 2005), Melbourne (Kenway et al. 2008, Kenway et al. 2014), and in other cities (Frost et al. 2016). A complete and inclusive city water account covering both direct water and virtual water inflows and outflows, and the decomposition of virtual water by source and destination regions, final demand, and major product categories are still missing. Therefore, an inclusive city water account by the simultaneous edition of both direct and virtual water is needed to ensure (i) direct water footprint reduction through investment in the efficient city water cycle (Koop and van Leeuwen 2015); (ii) water sensitive city planning (Renouf and Kenway 2017); (iii) to increase the resiliency and strategic city water footprint reduction through an inclusive and sustainable city water planning considering both adjacent and distant regions future water shock (Chini et al. 2017).

We present here the concept of an inclusive city water account for the Australian cities considering both direct and virtual water. We have demonstrated the inclusive city water account for SEQ (Brisbane, Goal Coast, and Sunshine Coast together). Our research has been conducted for the full economic sectors based on multiregional input-output (MRIO) modeling and integrating three national water data sets to obtain a comprehensive understanding of the national water footprint of SEQ. 
Islam et al., An inclusive city water account by integrating multiple data sources for South-East Queensland (SEQ), Australia

\section{METHODOLOGY}

\subsection{Accounting framework}

The accounting framework is based on a consumption-based water footprint consisting of direct and virtual water flow to SEQ (Chini et al. 2017). The material Flow Analysis (MFA) and Multi-regional Input-Output (MRIO) model is used to account for the direct and virtual water flow to SEQ through the inter-regional commodities and services trade. MRIO model is used to trace the virtual water inflow and outflow to and from the source and destination regions through the inter-regional product and service supply chain (Wiedmann 2017). MFA approach accounted for the direct water consumption to SEQ household and industrial sectors, and the direct water consumption of the industrial sectors used as water satellite for the MRIO modeling.

Let's assumed Q regions, and M sectors producing homogenous products. The balance of production activities in region $\mathrm{q}$ is presented in Equation 1 based on the fact that the total economic output (product and service) of an economy is equal to the intermediate product/service and final consumption.

$x q=A q q x q+y q q+\sum_{r \neq q} A q r x r+\sum_{r \neq q} y q r+E x q$

Here, $x q$ is the economic output in region $\mathrm{q}$ with $\mathrm{N} \times 1$ column vector dimension. $A q q$ is local direct requirement with $\mathrm{N} \times \mathrm{N}$ matrix dimension, of which $a_{s t}^{q q}$ represents each element. It means the input quantity from sector $\mathrm{s}$ in region $\mathrm{q}$ to produce one unit output in sector $\mathrm{t}$ of region $\mathrm{q}$. yqq is final demand of local production in region $\mathrm{q}$, with $\mathrm{N} \times 1$ vector dimension. The final demand consists of household, government, and business. Exq is the export from q to other regions, with $\mathrm{N} \times 1$ vector dimension. Aqr (inter-regional direct requirement matrix) and yqr (inter-regional final demand vector) are based on the similar definitions of Aqq and yqq.

Equation 1 can be modified to Equation 2 based on Leontief demand-pull model (Leontief 1970).

$\mathrm{X} \phi=\mathrm{A} \phi \mathrm{X} \phi+\mathrm{Y} \phi$

Here, aggregated economic output vector of all regions, $\mathrm{X} \phi=[\mathrm{x} 1, \mathrm{x} 2, \mathrm{x} 3, \ldots \ldots \ldots \ldots . \mathrm{xQ}]^{\mathrm{T}}$. $\mathrm{T}$ indicates transformation.

Aggregated inter-regional direct requirement matrix, $\mathrm{A} \phi=\left(\begin{array}{cccc}A 11 & A 12 & \cdots & A 1 Q \\ A 21 & A 22 & \cdots & A 2 Q \\ \vdots & \vdots & \ddots & \vdots \\ A Q 1 & A Q 2 & \cdots & A Q Q\end{array}\right)$

Aggregated vector of inter-regional final demand, $\mathrm{Y} \phi=\left[\begin{array}{lllllllll}\mathrm{y} 1, & \mathrm{y} 2, & \mathrm{y} 3, & \ldots . & \ldots . & \ldots . & \ldots . & \mathrm{yQ}\end{array}\right]^{\mathrm{T}}=$ $\left[\sum_{r} y 1 r+E x 1, \sum_{r} y 2 r+E x 2, \ldots \ldots, \sum_{r} y Q r+E x Q\right]^{\mathrm{T}}$. T represents transformation.

The industrial sector water consumption coefficient vector is presented in Equation 3 by rearranging Equation 2 .

$\mathrm{WC} \phi=\mathrm{f} \phi \mathrm{X} \phi=\mathrm{f} \phi(\mathrm{I}-\mathrm{A} \phi)-1 \mathrm{Y} \phi$

Here, WC $\phi$ is the final demand $(\mathrm{Y} \phi)$ driven water consumption. $\mathrm{f} \phi=[\mathrm{f} 1, \mathrm{f} 2, \mathrm{f} 3, \ldots \ldots \ldots \ldots$ fQ...... $\mathrm{f}]$ is water consumption coefficients, with $1 \times(\mathrm{N} \times \mathrm{Q})$ vector dimension by economic sectors and regions. The identical matrix with Q dimensions is represented by I. To account water footprint of the final demand of a region, the aggregate final demand vector $\mathrm{Y} \phi$ is substituted by the final demand vector of sector $\mathrm{s}$ in region $\mathrm{q}$.

Equations 4 and 5 are used to account for the virtual water export and import of region $\mathrm{q}$.

$\mathrm{VWE}, \mathrm{qr}=\mathrm{fq}(\mathrm{I}-\mathrm{Aqq})-1 \sum_{q \neq r} E x q r$

$\mathrm{VWI}, q \mathrm{r}=\mathrm{f} 1(\mathrm{I}-\mathrm{A} 11)-1 E x 1 q+\mathrm{f} 2(\mathrm{I}-\mathrm{A} 22)-1 E x 2 q+\ldots . .+\mathrm{fr}(\mathrm{I}-\mathrm{Arr})-1 \operatorname{Exr} q(r \neq q)$

Here, virtual water export (VWE,qr) and virtual water import (VWI,qr) from $q$ to $r$ region are represented, with export from q to $\mathrm{r}$ (Exqr), and export from $\mathrm{r}$ to $\mathrm{q}$ (Exrq).

\subsection{Case Study Data}

Brisbane, Gold Coast, and Sunshine Coast together represent SEQ. Bureau of Meteorology (BOM) National Performance city water data (BOM 2018) is used to account for the direct water flows. Australian Bureau of Statistics (ABS) Water Account (ABS 4610.0) at the state level for the year 2015 (ABS 2016a) is disaggregated at the city level for the first time based on Water consumption on Australian Farms at SA2 level (ABS 4618.0) (ABS 2016b), and BOM National Performance city water data (BOM 2018). The compiled city-level data were integrated into the Industrial Ecology Virtual Laboratory (IELab) to generate an MRIO table of 15 regions and 100 economic sectors. The IELab is a collaborative platform to generate MRIO data at high spatial and 
Islam et al., An inclusive city water account by integrating multiple data sources for South-East Queensland (SEQ), Australia

sectoral resolution (Wiedmann 2017). It can disaggregate the economic and environmental data at SA2 level (regions with a population of 10,000 residents) in Australia from proxy data, such as business turnover, employment, and income, household expenditure (Lenzen et al. 2017). To re-balance the MRIO table a nonsurvey method (Adjusted Flegg's location quotient) (Lenzen et al. 2014), and constrained-optimization algorithm called 'Konfliktfreies RAS (KRAS)' was used (Lenzen et al. 2017). Only the water flows within the Australian territory, and virtual water export to the rest of the world is accounted for, and virtual inflows from the rest of the world are not accounted for.

\section{RESULTS}

3.1. Inclusive city water account, and decomposition of source and destination regions of virtual water The inclusive city water account can inform the city planner about the water footprint of a city under different categories, and virtual water flows by source and destination regions. We demonstrate this by showing results for the SEQ case study.

Water footprint on national water resources amounts to $2002 \mathrm{GL}$, consisting of water footprint on local water resources (620 GL), and net virtual water import (1382 GL) (Figure 2). Water footprint on local water resources consists of household direct water consumption (192 GL), and industrial sector direct water consumption (428 GL). Industrial sector direct water consumption has become embodied in products consumed by the SEQ (149 GL) and exported as virtual water to other regions of Australia and the World (279 GL). Net virtual water import (1382 GL) represents virtual water imported from other regions of Australia (1661 GL) less virtual water export $(279 \mathrm{GL})$.

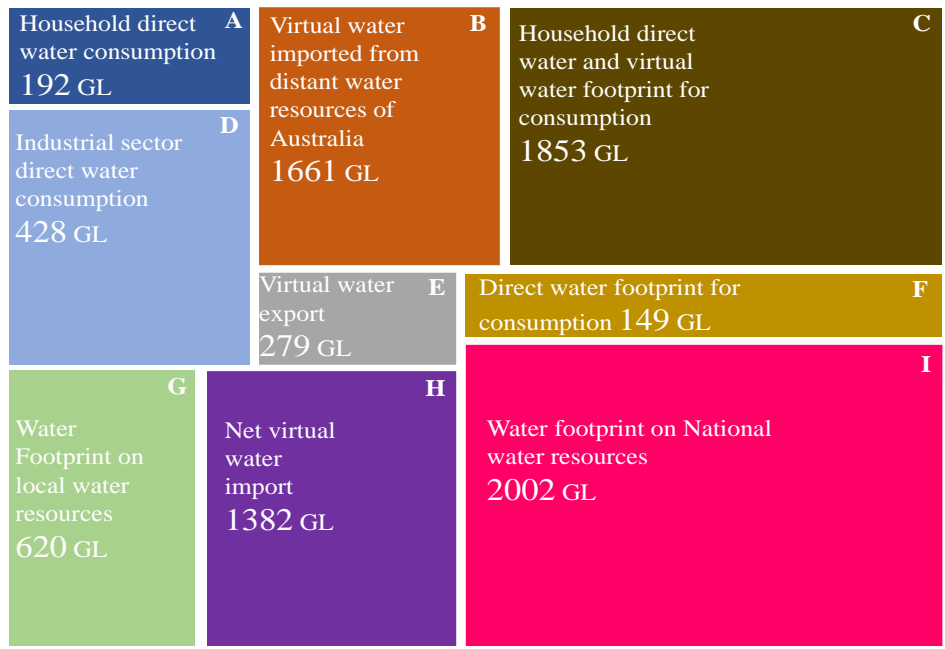

Figure 2. City water account of $S E Q$. Here, the accounting approaches are $A+B=C, D-E=F, A+D=G, B-$ $\mathrm{E}=\mathrm{H}, \mathrm{C}+\mathrm{F}=\mathrm{I}, \mathrm{G}+\mathrm{H}=\mathrm{I}$. SEQ-South East Queensland.

We have decomposed the inclusive city water account for the destination and source regions of virtual water. For simplification, we have decomposed the destination regions of virtual water from SEQ to SEQ, the rest of Australia (RoAUS) (all other regions of Australia except SEQ), and rest of the World (RoW). We have decomposed the source regions of virtual import to SEQ, by major capital cities (Sydney, Melbourne, Adelaide, and Perth), regional areas of NSW, Victoria, and QLD, and RoAUS to represent all other regions except the capital cities, and regional areas of NSW, Victoria, and QLD mentioned before.

Figure 3 presents the source and destination of virtual water flows to and from SEQ along with the direct water consumption by households (192 GL) and the industrial sector (428 GL). The destination regions of consumed direct water of the SEQ industrial sector as virtual water are SEQ (149 GL), RoAUS (211 GL), and RoW (68 GL). As shown in Figure 1, the total virtual water imported to SEQ from distant water resources of Australia is 1661. This virtual water import is decomposed by source regions as $386 \mathrm{GL}, 1019 \mathrm{GL}$, and $256 \mathrm{GL}$ from the major capital cities (Sydney, Melbourne, Adelaide, and Perth); regional areas of NSW, Victoria, and QLD; and RoAUS, respectively.

The per capita direct and virtual water footprint of SEQ is $776 \mathrm{~kL}$, which is consisting of direct water consumed by SEQ households (8\%), the industrial sector (19\%), and virtual water import from other regions of Australia (73\%). The per capita direct and virtual water footprint of SEQ less virtual water exported to other regions of Australia represents the per capita water footprint of SEQ on national water resources $681 \mathrm{~kL}$ ( $776-95 \mathrm{~kL})$. We aggregate the final demand categories into three categories to represent the key actors in a city: households, 
Islam et al., An inclusive city water account by integrating multiple data sources for South-East Queensland (SEQ), Australia

government, and businesses. Whereas households are responsible for the majority of SEQ's water footprint $(53 \%, 415 \mathrm{~kL} / \mathrm{cap})$, both government (12\%), and business demand (35\%) also contribute significantly (Figure 4).

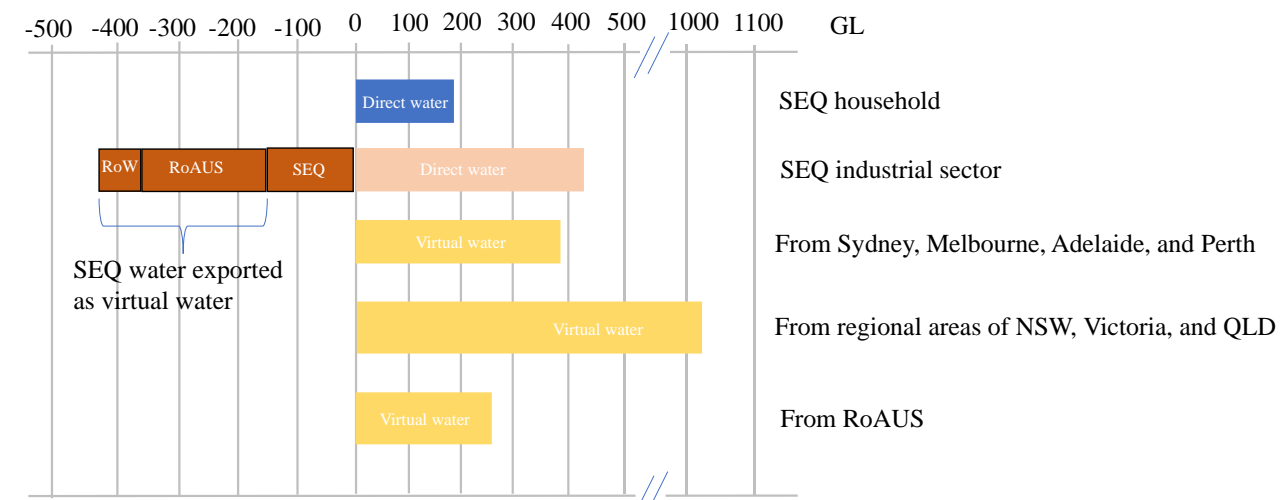

Figure 3. Decomposition of origin and destination of SEQ's water flows. SEQ-South East Queensland.

\subsection{Per capita decomposition of direct and virtual water by source and destination regions, final demand, and major sector}

We have also decomposed the per capita virtual water footprint of the final demand of SEQ by broad product category and origin (Figure 5). Of the per capita virtual water footprint of agriculture products (61 kL), 67\% originated from the regional areas of NSW, Victoria, and QLD; and 21\% from the RoAUS. Of the per capita virtual water footprint of processed food products $(171 \mathrm{~kL}), \sim 73 \%$ originated from the regional areas of NSW, Victoria, and QLD; and 18\% from major capital cities (Sydney, Melbourne, Adelaide, and Perth). Of the per capita virtual water footprint of construction $(55 \mathrm{~kL})$ and service sectors $(188 \mathrm{~kL})$, more than $55-70 \%$ originated from the major capital cities (Sydney, Melbourne, Adelaide, and Perth) and SEQ. Of the per capita virtual water footprint of the electricity sector $(21 \mathrm{~kL}), \sim 48 \%$ and $23 \%$ originated from SEQ, and regional areas of QLD, respectively.

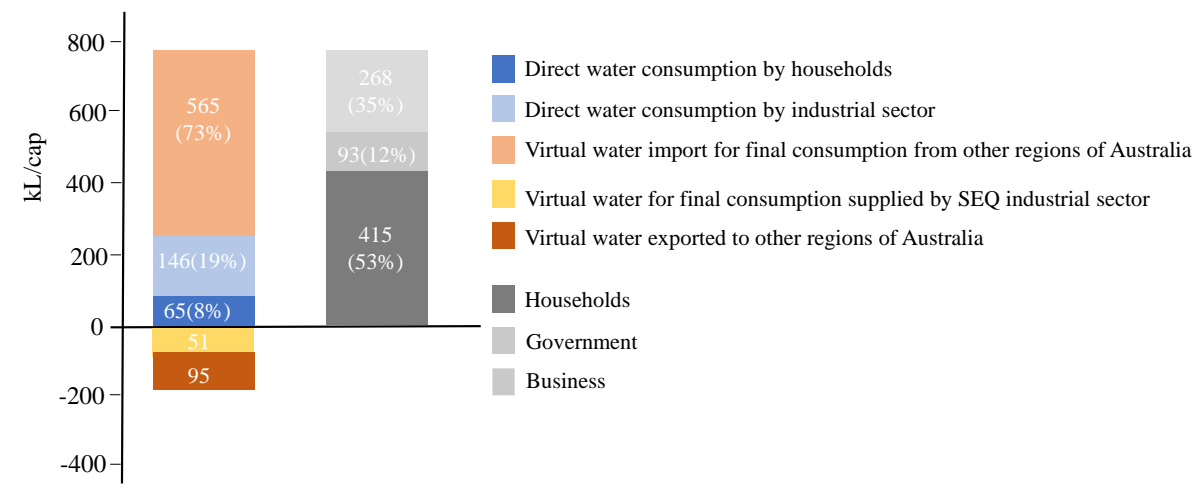

Figure 4. Per capita decomposition of direct and virtual water by source and destination regions, and type of final demand (in parenthesis percentages are shown). SEQ-South East Queensland.

\section{DISCUSSION AND CONCLUSION}

An inclusive city water accounting covering direct and virtual water will help SEQ to understand the dependencies of the cities (Brisbane, Goal Coast, and Sunshine Coast) economy and consumption of Australian water resources. It will help to identify the magnitude of dependencies, when and where supply security vulnerability may arise due to water shortage; and accordingly to plan (Mekonnen et al. 2015). This has profound implications for the food and economic security of the SEQ, and ultimately to develop strategic cooperation with virtual water supplying regions for protecting and maintaining water resources there, together with local water resources of SEQ (Garcia et al. 2020). Due to increasing national (also global) water scarcity and stress (Bontinck et al. 2021), SEQ needs reliable and sustainable direct and virtual water supplies, and accordingly strategic planning to ensure supply security (Ridoutt et al. 2014). As mention in the introduction, the cities of the SEQ region have strategic vision and sustainability targets focusing on direct water, which is an example of weak sustainability. To ensure strong sustainability for the SEQ, it requires knowing both direct 
Islam et al., An inclusive city water account by integrating multiple data sources for South-East Queensland (SEQ), Australia

and virtual water need to meet the necessity of the economy and final consumption. Hence, accurately mapping and quantifying both direct and virtual water flows through an inclusive city water account.

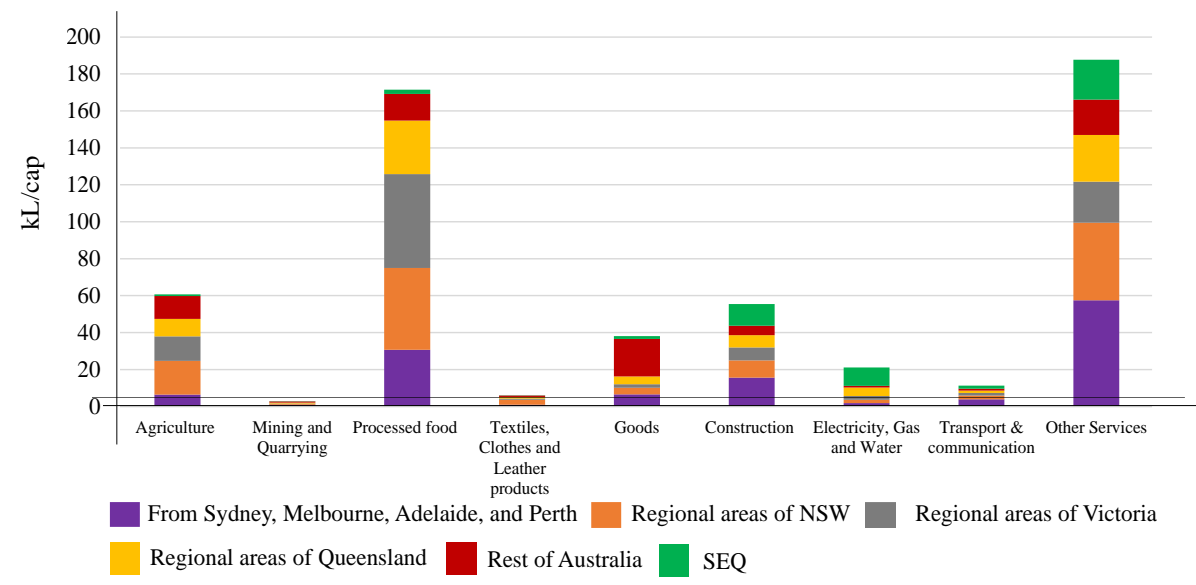

Figure 5. Per capita decomposition of virtual water of SEQ's final demand by broad product category and Origin. SEQ-South East Queensland.

A barrier to the accounting of virtual water for city planning and water-sensitive city design is a lack of knowledge and data (Renouf and Kenway 2017). This gap could, in part, be covered by the multi-regional input-output data at a high level of sectoral and spatial resolution from IELab (Wiedmann et al. 2016), which we demonstrate here through an inclusive city water account of SEQ. Such inclusive city water account can help the local governments to direct water demand reduction strategies focusing on direct and virtual water, and go beyond merely identifying high water-consuming sectors to relocation planning of those sectors to water abundant regions from scarce regions (Lenzen and Peters 2010). Considering these critical aspects, we present the concept of inclusive city water account for SEQ based on the MRIO modeling. We conclude:

- The inclusive city water account links the water footprint to adjacent and distant water resources at multiple spatial scales by national and global distant regions through nesting the city MRIO data with sub-regions in a country and global MRIO data; and

- Using SEQ as a case study, we demonstrate water footprint of SEQ on Australian water resources amounts to $2002 \mathrm{GL}$, consisting of SEQ local water resources (620 GL), and $1382 \mathrm{GL}$ net virtual water import.

\section{ACKNOWLEDGMENTS}

This work is funded by the University of Queensland Research Training Program (UQ RTP) scholarship, and the Australian Research Council (ARC) DECRA project DE160101322.

\section{REFERENCES}

ABS (2016a) Water Account, Australia, 2014-15. , Australian Bureau of Statistics (ABS), Canberra, Australia. ABS (2016b) Water Use on Australian Farms, 2014-15. , Australian Bureau of Statistics (ABS), Canberra, Australia.

Athanassiadis, A., Christis, M., Bouillard, P., Vercalsteren, A., Crawford, R.H. and Khan, A.Z. (2018) Comparing a territorial-based and a consumption-based approach to assess the local and global environmental performance of cities. Journal of Cleaner Production 173, 112-123.

BCC (2010) WaterSmart Strategy, p. 45, Brisbane City Council (BCC), Brisbane, Australia.

Beal, C., Stewart, R., Huang, T. and Rey, E. (2011) South East Queensland residential end use study, Urban Water Security Research Alliance Brisbane, Australia.

BOM (2018) National performance report 2016-17: urban water utilities, p. 121, Bureau of Meteorology (BOM), Australian Government, Melbourne, Victoria.

Bontinck, P.-A., Grant, T., Kaewmai, R. and Musikavong, C. (2021) Recalculating Australian water scarcity characterisation factors using the AWARE method. The International Journal of Life Cycle Assessment, 115.

Chini, C.M., Konar, M. and Stillwell, A.S. (2017) Direct and indirect urban water footprints of the United States. Water Resources Research 53(1), 316-327.

Frost, L., Gaynor, A., Gregory, J., Morgan, R., O’Hanlon, S., Spearritt, P. and Young, P. (2016) Water, history and the Australian city: urbanism, suburbanism and water in a dry continent, 1788-2015, p. 63, Cooperative Research Centre for Water Sensitive Cities, Melbourne, Australia. 
Islam et al., An inclusive city water account by integrating multiple data sources for South-East Queensland (SEQ), Australia

Garcia, S., Rushforth, R., Ruddell, B.L. and Mejia, A. (2020) Full domestic supply chains of blue virtual water flows estimated for major US cities. Water Resources Research 56(4), 1-20.

GCCC (2019) Gold Coast Water Strategy 2019-2024, p. 40, Gold Coast City Council (GCCC), Gold Coast, Australia. .

Kenway, S., Turner, G., Cook, S. and Baynes, T. (2008) Water-energy futures for Melbourne: the effect of water strategies, water use and urban form, Citeseer.

Kenway, S., Turner, G., Cook, S. and Baynes, T. (2014) Water and energy futures for Melbourne: implications of land use, water use, and water supply strategy. Journal of Water Climate Change 5(2), 163-175.

Koop, S.H. and van Leeuwen, C.J. (2015) Assessment of the sustainability of water resources management: a critical review of the city blueprint approach. Water resources management 29(15), 5649-5670.

Lenzen, M. (2009) Understanding virtual water flows: A multiregion input-output case study of Victoria. Water Resources Research 45(9).

Lenzen, M. and Foran, B. (2001) An input-output analysis of Australian water usage. Water Policy 3(4), 321340.

Lenzen, M., Geschke, A., Malik, A., Fry, J., Lane, J., Wiedmann, T., Kenway, S., Hoang, K. and CadoganCowper, A. (2017) New multi-regional input-output databases for Australia-enabling timely and flexible regional analysis. Economic Systems Research 29(2), 275-295.

Lenzen, M., Geschke, A., Wiedmann, T., Lane, J., Anderson, N., Baynes, T., Boland, J., Daniels, P., Dey, C. and Fry, J. (2014) Compiling and using input-output frameworks through collaborative virtual laboratories. Science of the Total Environment 485, 241-251.

Lenzen, M. and Peters, G.M. (2010) How city dwellers affect their resource hinterland: A Spatial Impact Study of Australian Households. Journal of Industrial Ecology 14(1), 73-90.

Leontief, W. (1970) Environmental repercussions and the economic structure: an input-output approach. Review of economics statistics 52(3), 262-271.

McDonald, R.I., Weber, K., Padowski, J., Flörke, M., Schneider, C., Green, P.A., Gleeson, T., Eckman, S., Lehner, B. and Balk, D. (2014) Water on an urban planet: Urbanization and the reach of urban water infrastructure. Global environmental change 27, 96-105.

Mekonnen, M.M., Pahlow, M., Aldaya, M.M., Zarate, E. and Hoekstra, A.Y. (2015) Sustainability, efficiency and equitability of water consumption and pollution in Latin America and the Caribbean. Sustainability 7(2), 2086-2112.

Randolph, B. and Troy, P. (2007) Understanding Water Consumption in Sydney, pp. 900-911, Australian Cities Research Network (ACRN), University of South Australia, Flinders University, The University of Adelaide, Adelaide, Australia

Renouf, M., Serrao-Neumann, S., Kenway, S., Morgan, E. and Choy, D.L. (2017) Urban water metabolism indicators derived from a water mass balance-Bridging the gap between visions and performance assessment of urban water resource management. Water research 122, 669-677.

Renouf, M.A. and Kenway, S. (2017) Evaluation approaches for advancing urban water goals. Journal of Industrial Ecology 21(4), 995-1009.

Reutter, B., Lant, P.A. and Lane, J.L. (2018) Direct and indirect water use within the Australian economy. Water Policy 20(6), 1227-1239.

Ridoutt, B.G., Hadjikakou, M., Nolan, M. and Bryan, B.A. (2018) From water use to water scarcity footprinting in environmentally extended input-output analysis. Environmental science \& technology.

Ridoutt, B.G., Page, G., Opie, K., Huang, J. and Bellotti, W. (2014) Carbon, water and land use footprints of beef cattle production systems in southern Australia. Journal of Cleaner Production 73, 24-30.

SCCC (2017) Environment and Liveability Strategy 2017, p. 89, Sunshine Coast City Council (SCCC), Sunshine Coast, Australia

Troy, P., Holloway, D. and Randolph, B. (2005) Water Use and the Built Environment: Patterns of Water Consumption in Sydney p. 82, City Futures Research Centre, University of New South Wales, New South Wales.

Wiedmann, T. (2017) An input-output virtual laboratory in practice-survey of uptake, usage and applications of the first operational IELab. Economic Systems Research 29(2), 296-312.

Wiedmann, T.O., Chen, G. and Barrett, J. (2016) The concept of city carbon maps: a case study of Melbourne, Australia. Journal of Industrial Ecology 20(4), 676-691.

Wolman, A. (1965) The metabolism of cities. Scientific American 213(3), 178-193. 